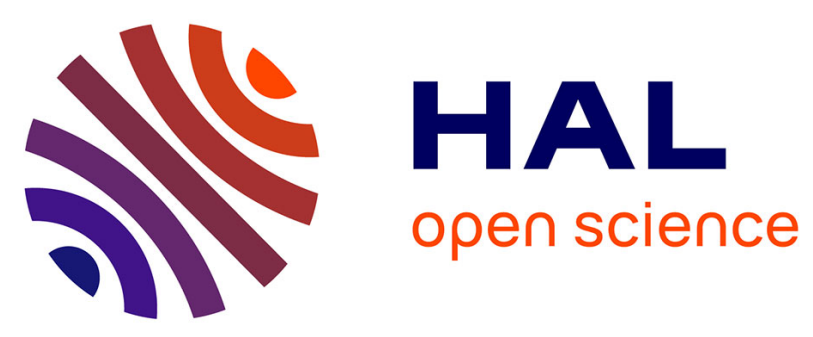

\title{
On the evolution of the viscoelastic properties and its microstructural/chemical origin in filled NBR subjected to coupled thermal and mechanical loads
}

P. Garnier, Jean-Benoit Le Cam, Michel Grediac, M. Grédiac, Soraya Ababou-Girard, M. Dubois

\section{To cite this version:}

P. Garnier, Jean-Benoit Le Cam, Michel Grediac, M. Grédiac, Soraya Ababou-Girard, et al.. On the evolution of the viscoelastic properties and its microstructural/chemical origin in filled NBR subjected to coupled thermal and mechanical loads. Polymer Degradation and Stability, 2013, 98, pp.2102-2110. 10.1016/j.polymdegradstab.2013.06.028 . hal-01131574v2

\author{
HAL Id: hal-01131574 \\ https://hal.science/hal-01131574v2
}

Submitted on 25 May 2020

HAL is a multi-disciplinary open access archive for the deposit and dissemination of scientific research documents, whether they are published or not. The documents may come from teaching and research institutions in France or abroad, or from public or private research centers.
L'archive ouverte pluridisciplinaire HAL, est destinée au dépôt et à la diffusion de documents scientifiques de niveau recherche, publiés ou non, émanant des établissements d'enseignement et de recherche français ou étrangers, des laboratoires publics ou privés. 


\title{
On the evolution of the viscoelastic properties and its microstructural/chemical origin in
}

\section{filled NBR sujected to coupled thermal and mechanical loads}

\author{
P. Garnier ${ }^{\mathrm{a}, \mathrm{b}, \mathrm{c}}$, J.-B. Le Cam ${ }^{\mathrm{b}, 1}$, M. Grédiac ${ }^{\mathrm{a}}$, \\ S. Ababou-Girard ${ }^{\mathrm{d}}$ and M. Dubois ${ }^{\mathrm{e}}$ \\ ${ }^{a}$ Université Blaise Pascal-Institut Français de Mécanique Avancée, Institut Pascal, \\ UMR CNRS 6002, BP 265, 63175 Clermont-Ferrand, France \\ ${ }^{\mathrm{b}}$ Université de Rennes 1, LARMAUR, ERL CNRS 6274, Campus de Beaulieu, \\ 35042 Rennes Cedex, France \\ ${ }^{\mathrm{c}}$ PCM, 1 Rue René Moineau, F-49000 CHAMPTOCÉ SUR LOIRE, France \\ d Université de Rennes 1, IPR, UMR CNRS 6251, Département Matériaux \\ Nanosciences, Campus de Beaulieu, 35042 Rennes Cedex, France \\ e Université Blaise Pascal, Laboratoire des Matériaux Inorganiques, UMR 6002 \\ CNRS, Aubière 63177, France
}

\begin{abstract}
This study deals with the effect of coupled thermal and cyclic mechanical loadings on the viscoelastic response of carbon black filled nitrile rubber. For this purpose, cyclic loading tests were performed at different temperatures by means of Dynamic Mechanical and Thermal Analysis (DMTA). The type and level of the thermomechanical loadings applied were chosen in order to determine the relative contribution
\end{abstract}


of each of the mechanical and thermal loadings (and their coupling) to the viscoelastic response during the cyclic tests. X-ray photoemission spectroscopy (XPS) and Fourier Transformed Infrared spectroscopy (FTIR) analyses were also carried out to track the change in the chemical structure corresponding to the evolution in the viscoelastic response. First, results obtained show that due to the crosslink increase, the storage modulus increases with the number of cycles. It is also observed that temperature amplifies this phenomenon. Second, the cyclic mechanical loading is found to significantly amplify the effect of temperature.

Key words: nitrile rubber, viscoelasticity, vulcanization, temperature effects, mechanical effects, microstucture evolution

1 Corresponding author : J.-B. Le Cam, Université de Rennes 1, LARMAUR, ERL CNRS 6274, Campus de Beaulieu, 35042 RENNES Cedex, France, Email: jeanbenoit.lecam@univ-rennes1.fr 


\section{Introduction}

Most of the studies dealing with damage in rubbers under mechanical cyclic loading conditions focus on damage, which corresponds to crack initiation and growth until final failure (see for instance [1]). These purely mechanical studies investigate the effects of uniaxial or multiaxial loading conditions on fatigue damage. Generally, cyclic loading conditions lead to strain level whose amplitude can reach up to several hundreds of percent $[1,2,3,4]$. However, many industrial applications involve loading conditions and strain levels that are different from the abovementioned ones, in particular compression-compression or relaxing compression with low cyclic strain level at high temperatures. To the best of the authors' knowledge, these types of cyclic loading conditions have never been studied previously for filled nitrile rubbers.

For the nitrile rubbers studied in the present paper, preliminary tests under such loading conditions have shown that damage does not correspond to crack initiation and growth but to a significant change in the microstructure. These changes induce both a variation of the initial viscoelastic properties and a hardness increase. Consequently, by focusing on possible applications, the rubber part loses its damping properties.

The aim of the present paper is first to characterize the change in viscoelastic properties, i.e. in the microstructure, in filled nitrile rubber under cyclic compression-compression loading conditions and at various temperatures. Then, the effect of the mechanical loading on the change in the microstructure is investigated in order to define if it influences the response or not. An original cyclic and thermal mechanical test has been carried out for this purpose.

Section 2 deals with the materials and methods used in this study. The two 
types of loading conditions applied (thermal and mechanical) as well as their coupling are described. Results obtained are presented and discussed in Section 3. As numerous results are presented in this paper, they are summed up before concluding.

\section{Material and methods}

\subsection{Material and specimen geometry}

The material tested in this study is a nitrile filled with $35 \mathrm{phr}^{2}$ of carbon black, with a small amount of mineral fillers. It was vulcanized with sulphur. The following procedure was used to prepare the specimens : (i) a bar was first obtained by compression moulding; (ii) this bar was then cut with a water jet cutting device to obtain specimens of lower size: $5 \times 5 \mathrm{~mm}^{2}$ square cross-section and $5 \mathrm{~mm}$ in height.

The resulting low aspect ratio is justified by the fact that buckling, which might occur during the compressive tests, is avoided. It is worth noting that this type of cutting technology (water jet cutting) avoids microstructural damage on the specimen surface.

\subsection{Dynamic Mechanical Analysis (DMA)}

The viscoelastic properties of rubber were measured by means of a Metravib VA2000 viscoanalyzer. First, each specimen to be tested was placed between two compression plates fixed on the grips. A uniaxial cyclic loading was then

$\overline{2 \text { parts }}$ per hundred parts of rubber in weight 
applied to the specimen by a shaker connected to the upper grip. A force sensor located under the lower grip recorded the force sustained by the specimen, while a displacement sensor measured the displacement of the upper grip. The DMA analysis provides the force and displacement signals and automatically calculates the elastic modulus $E^{\prime}$ and the loss factor $\tan \delta$.

In case of significant geometric changes during the experiment, $E^{\prime}$ must be corrected by using the current geometry instead of the initial one. The strain and stress are also computed by taking into account the variation in height. This means that $h_{-5 N}$, which is the height at the maximum value of the applied force signal, is chosen instead of $h_{\text {initial }}$ when computing the strain and that the section is that at the maximal load $-5 \mathrm{~N}$ denoted $s_{-5 N}$ when computing the stress. $s_{-5 N}$ is defined assuming that the material remains incompressible. Thus :

$$
V=h_{\text {initial }} * s_{\text {initial }}=h_{-5 N} * s_{-5 N}=>s_{-5 N}=\frac{V}{h_{-5 N}}
$$

where $V$ is the volume of the specimen. These two corrections lead to a more realistic assessment of $E^{\prime}$ in the case of significant change in geometry.

\subsection{Loading conditions}

As mentioned above, the tests are aimed at investigating the effect of the thermal and mechanical loadings and their coupling on the microstructure evolution. Three types of tests were performed for this purpose, using different thermal and mechanical loadings. These tests are presented hereafter. 


\subsubsection{Coupled thermal and mechanical tests}

The first type of test consisted in applying both a high temperature and a mechanical load at the same time (see Fig. 1-a). To stick to the underlying industrial application, the mechanical loading corresponds to a sinusoidal compression at a frequency of $10 \mathrm{~Hz}$. The tests were performed under prescribed force. This induces geometric variations of the specimens. Three values of Double Force Amplitude (DFA, defined as the peak-to-peak amplitude) were chosen: 15, 30, $50 \mathrm{~N}$. These force values correspond to a stress of 0.6, 1.2 and $2 \mathrm{MPa}$ respectively. For each test, the maximal force value applied was $-5 \mathrm{~N}$ in order to prevent the specimen to move along the grip during the experiments. Three temperatures were applied: 140,160 and $180{ }^{\circ} \mathrm{C}$. Thus, combined to three mechanical loading levels, nine different tests are defined. During one of the three tests performed at $180{ }^{\circ} \mathrm{C}$, another specimen was placed in the temperature-controlled chamber. It serves as a reference specimen, which only underwent the thermal load during the test duration. It is worth noting that only one specimen per temperature and load level could be tested because of the duration of each test. This leads to ten tests which are described in Table 1 . The values of the force and temperature were chosen after some preliminary tests which are not reported here. Each test lasted one million cycles (28 hours at $10 \mathrm{~Hz})$.

\subsubsection{Uncoupled thermal and mechanical tests}

Classically, the microstructure evolution is thought to be mainly due to high temperature levels. One can however legitimately wonder whether a mechanical loading influences or not this evolution. These uncoupled tests are therefore aimed at defining the contribution of the mechanical load on the microstruc- 
Table 1

Summary of the coupled thermal and mechanical tests.

\begin{tabular}{|c|c|c|}
\hline Name & Temperature $\left[{ }^{\circ} \mathrm{C}\right]$ & DFA $[\mathrm{N}]$ \\
\hline T140F15 & 140 & 15 \\
\hline T140F30 & 140 & 30 \\
\hline T140F50 & 140 & 50 \\
\hline T160F15 & 160 & 15 \\
\hline T160F30 & 160 & 30 \\
\hline T160F50 & 160 & 50 \\
\hline T180F15 & 180 & 15 \\
\hline T180F30 & 180 & 30 \\
\hline T180F50 & 180 & 50 \\
\hline T180 & 180 & 0 \\
\hline
\end{tabular}

ture evolution under high temperatures levels. The first test consists in applying first a thermal load $\left(140,160\right.$ or $\left.180{ }^{\circ} \mathrm{C}\right)$ during 28 hours, and then in applying a cyclic mechanical load at a DFA of $50 \mathrm{~N}$ during one million cycles at ambient temperature (see Fig. 1-b). Since no mechanical load was applied to the specimen during the first part of the test, the viscoelastic properties were not characterized. Only the initial, the intermediate (after the first step) and final hardness as well as the geometry were measured for these three tests.

To solve the problem of the viscoelasticity properties monitoring during the thermal load step, another series of experiments was carried out. The first objective is to observe their evolutions under a constant thermal load. The second objective is to detect possible couplings between temperature and stress. These two objectives are reached by performing a repeated sequence of two loading steps (see Fig. 1-c):

- during the first step, named the thermal step and denoted TS in the following, a very low strain (considered as almost null, corresponding to a displacement range of $0.025 \mathrm{~mm})$ at a low frequency $(2.5 \mathrm{~Hz})$ was applied during 9000 cycles (one hour);

- during the second step, named the thermomechanical step and denoted TMS 
in the following, the mechanical loading of the first series $(15,30$ and $50 \mathrm{~N}$ at $10 \mathrm{~Hz}$ ) is applied during 500 cycles (50 seconds).

This sequence is repeated 24 times. Comparing the viscoelastic properties at the end of $\operatorname{TMS}(i)$ with those obtained at the beginning of $\operatorname{TMS}(i+1)$ enables one to track their variations during TS $(i)$. Observing the changes in the viscoelastic properties during $\operatorname{TMS}(i)$ gives an information about the effect of the coupling between thermal and mechanical loads on the viscoelastic response of the material. Thanks to each TMS, it was possible to regularly record the mechanical properties during a long heating step. This was not possible with the previous series described in section 2.3.1 above. The influence of each TMS on the kinetics of the microstructure change (if any) is assumed to be negligible here because of its very short duration.

\subsection{Fourier Transform Infrared spectroscopy (FTIR)}

Several specimens picked in the series described in section 2.3.2 above were analysed with FTIR spectroscopy. These analyses were performed in order to observe chemical changes in the rubber microstructure after thermal and/or mechanical loads. A virgin specimen was therefore analysed to give the reference spectrum. FTIR spectroscopy results were recorded on a ThermoNicolet 5700 spectrometer equipped with a Smart Orbit diamond ATR device. 128 scans were collected at room temperature in the $450-4000 \mathrm{~cm}^{-1}$ range, with a $4 \mathrm{~cm}^{-1}$ resolution. 


\subsection{X-ray Photoelectron Spectroscopy (XPS)}

XPS analyses were also performed on some specimens : T180F50, T180 and a virgin specimen. The XPS experiments were carried out in a home-built Ultra-High Vacuum chamber equipped with a hemispherical energy analyser, using a MgK source $(1253.6 \mathrm{eV})$ operating at $240 \mathrm{~W}$. The base pressure in the chambers was around $10^{-8} \mathrm{~Pa}$. The measurements were carried out at room temperature. The data acquisition includes:

- a wide scan from 0 to $1200 \mathrm{eV}$ at a pass energy of $50 \mathrm{eV}$ and a step size of $0.5 \mathrm{eV}$

- narrow scans for all core levels at $20 \mathrm{eV}$ and a step size of $0.1 \mathrm{eV}$.

Each spectral region was scanned three times to get an acceptable signal-tonoise ratio within a reasonable acquisition time. The spectra are subjected to a Shirley background subtraction formalism and the binding energy scale is calibrated with respect to the $C_{1 s}$ peak at $285 \mathrm{eV}$.

\section{Results}

In this section, results obtained by performing the coupled thermal and mechanical tests are first presented. They are followed by those obtained with the uncoupled mechanical and thermal tests. 


\subsection{Coupled thermomechanical loadings}

\subsubsection{Hardness measurements}

Hardness measurements were performed on all the specimens before and after testing using a Zwick durometer. This enables us to measure the change in hardness denoted $\Delta H\left(\Delta H=H_{\text {final }}-H_{\text {initial }}\right)$ due to the applied loads. All the specimens come from the same batch and have an initial hardness equal to $70 \mathrm{Sh}$ A. Figure 2 shows that for the experiments performed at $15 \mathrm{~N}, H_{\text {final }}$ increases from 76 to $84 \mathrm{Sh} \mathrm{A}$ when the temperature increases from $140{ }^{\circ} \mathrm{C}$ to $180{ }^{\circ} \mathrm{C}$. For the tests run at $30 \mathrm{~N}, H_{\text {final }}$ is the same at $140{ }^{\circ} \mathrm{C}$ and at $160{ }^{\circ} \mathrm{C}$ (75 Sh A). It is higher at $180{ }^{\circ} \mathrm{C}(81 \mathrm{Sh} \mathrm{A})$. The quality of such measurements strongly depends on the flatness of the face where they are performed as well as on the parallelism between this face and the opposite one. A strong geometric evolution was observed for the T180F30, T180F50, T160F50 specimens. This led faces not to be parallel anymore. Hence, it was not possible to measure correctly $H_{\text {final }}$ for these three specimens after testing. From a qualitative point of view, it can only be said that $H_{\text {final }}>H_{\text {initial }}$.

The hardness measurements carried out after each of the nine tests reveal a significant evolution in the material microstructure. It must be noted that the hardness here is a qualitative and global indicator of material evolution which strongly depends on the quality of the specimen geometry. In addition, since hardness cannot be monitored during the tests, it is not useful to track and to understand the kinetics of the material evolution. To collect more relevant information, viscoelastic parameters $\left(E^{\prime}\right.$ and $\left.\tan \delta\right)$ were monitored, as explained below. 


\subsubsection{Viscoelastic property evolution}

Figure 3 shows the evolution of $E^{\prime}$ during the nine tests. For the sake of simplicity, these curves are reported and ordered by increasing DFA in Figures 4, 5, 6, and in Figure 7 for the three tests performed at $180{ }^{\circ} \mathrm{C}$. For each test, $\Delta E^{\prime}=E_{\text {final }}^{\prime}-E_{\text {initial }}^{\prime}>0$, irrespective to the DFA and temperature values. Thus, any combination of temperature and DFA leads to an increase in rigidity. This is an important result since an increase in temperature usually reduces $E^{\prime}$. Figure 3 shows the values of $E_{\text {initial }}^{\prime}$ for the six tests performed for a DFA of $30 \mathrm{~N}$ and $50 \mathrm{~N}$. These quantities are very close. $E_{\text {initial }}^{\prime}$ is slightly higher for the three tests performed at $15 \mathrm{~N}$. It must be noted that $E_{\text {final }}^{\prime}$ increases when the temperature increases for each DFA. It means that the temperature is one of the causes of the increase in rigidity. Before discussing on the loss factor evolution, these first results must be analyzed in light of the specimen geometry changes during the tests performed at 30 and $50 \mathrm{~N}$. Indeed, there is a flattening which consists in a decrease in height $h$ and in an increase in the cross-section which satisfies the incompressible material hypothesis. As a consequence, the uniaxial Cauchy stress decreases because of the section increase. It seems that heat induces a high macromolecular mobility and therefore a possibility for the rubber chains to reorganize according to the applied load. For a given DFA, the higher the temperature, the more significant the geometric evolution. This reorganization is also driven by the DFA: for the same temperature, the higher the force, the greater the geometrical evolution (see Figure 8). The evolution of the height begins to be significant when the DFA $\geq$ $30 \mathrm{~N}$ and $\mathrm{T} \geq 160^{\circ} \mathrm{C}$. The macromolecular reorganization mainly occurs during the early stages of the experiments $\left(2.10^{5}\right.$ cycles, see Figure 8$)$. It must be pointed out that the geometry of the specimens strongly changes at the beginning of the tests. This phenomenon has a strong impact on the stress 
and strain levels sustained by the specimens during the tests since these levels are different from the initial ones. In other words a high force level leads to a significant and fast flattening which strongly reduces the stress and strain levels. Hence considering only the initial stress and strain values and not the current ones could be really misleading. Most of the experiments were thereby carried out at a much lower stress than the initial one: an increase in initial force does not induce a proportional increase in stress. As a result, this test does not allow us to draw any conclusion concerning the effect of the DFA on the hardening process.

Another point is that no flattening occurs for the lowest DFA (15 N). So the evolution of $E^{\prime}$ (Figure 4) can only be due to an intrinsic change in the material behaviour. To sum up, an increase in temperature causes an increase in $\Delta E^{\prime}$ for each DFA. Besides, the effect of the mechanical load on $\Delta E^{\prime}$ is difficult to evaluate because of the variation in the specimen geometry.

The loss factor $\tan \delta$, which is a relevant indicator of the viscous behaviour of the rubber material, also evolves during the tests. The main trend for $\tan \delta$ (not reported in this study) is a decrease after or not any prior increase. This phenomenon corresponds physically to a decrease in the contribution of the viscosity to the mechanical response. The combined change in $E^{\prime}$ and $\tan \delta$ shows that the material evolution consists both of an increase in rigidity and a loss of viscosity at the same time. There is therefore a correspondence between the increase in hardness and the combined evolution of the viscoelastic parameters $E^{\prime}$ and $\tan \delta$.

This evolution under a high thermal load is expected for a rubber material. It is due to an over-vulcanization, which consists in the recombination of sulphur bonds between macromolecules. Classically, vulcanization of raw blend 
is obtained by applying a high temperature to the mold. The interesting thing here is that the high temperature is combined to a compressive loading and the influence on vulcanization is significant.

\subsection{Second series: uncoupled tests}

For the first attempt, the test was composed of two steps that are presented in Fig. 1-b). There was only a thermal load during the first step (140, 160, $180{ }^{\circ} \mathrm{C}$ for $28 \mathrm{~h}$ ), and only a cyclic mechanical loading during the second one (one million cycles at $10 \mathrm{~Hz}$, a DFA of $50 \mathrm{~N}, 28$ hours at ambient temperature). Interestingly and contrary to the preceding case, no flattening was observed at the end of the tests.

The hardness and the mechanical parameters are now investigated in detail. At the end of the first step, the hardness was found to be equal to $77 \mathrm{Sh} \mathrm{A}$, 79 Sh A and 87 Sh A at $140{ }^{\circ} \mathrm{C}, 160{ }^{\circ} \mathrm{C}$ and $180{ }^{\circ} \mathrm{C}$, respectively. Thus, the hardness increases here without any mechanical load. This is expected as vulcanization occurs without mechanical load.

Another interesting remark is that the hardness does not change between the end of the first step and the end of the test, thus meaning there is no observable influence of the mechanical load on vulcanization without high temperature. To sum up:

- the vulcanization process needs a thermal activation to occur ;

- the geometrical changes need the combination of both the thermal and the mechanical loads to occur.

Concerning the viscoelastic properties, $E^{\prime}$ was recorded only during the second 
step of the test (see Figure 10). $E^{\prime}$ does not evolve during the mechanical load step whatever the thermal load level in the previous step. $E^{\prime}$ is not recorded during the thermal step. Thus, it is not possible to observe the kinetics of the vulcanization during the thermal load. The second type of tests was therefore performed in order to regularly record $E^{\prime}$ during a long thermal load step.

\subsection{Monitored uncoupled tests}

Nine tests were performed ( 3 temperatures $\times 3$ DFAs). They consists in performing twenty-four sequences of one TMS (thermomechanical step) and one TS (thermal step) using the previous temperature and DFA values (see Figure 1-c)). The short TMS was performed to record $E^{\prime}$ regularly during the thermal load, so that it was possible to track the kinetics of the variations of the viscoelastic parameters during the TMSs. It also allows gives access to the value of the viscoelastic parameters at the beginning and the end of each TS. During any TS, a quasi-null load was applied $(0.1 \mathrm{~N})$ because the viscoanalyser can not work with a rigorously null load. During each test, the specimen was subjected to a total of $1.2510^{4}$ cycles (25 TMS of 500 cycles), which is very low compared to the $10^{6}$ cycles applied during the preceding tests. $E^{\prime}$ is recorded during each TMS (see Fig. 11). Thus, the diagram representing $E^{\prime}$ during one test contains 25 curves corresponding to the 25 TMSs. The whole campaign is summed up in the 3 X 3 matrix shown in Figure 11. The DFA increases along the columns and the temperature along the lines.

The sets of curves must be analysed by examining the following features:

- the width of each group of curves $\left(\Delta E^{\prime}\right)$;

- the height of each group of curves $\left(E_{\text {init }}^{\prime}\right)$; 
- the relative position of each successive curves;

- the monotony of each curve;

Some differences clearly appear between these nine results:

- for a given DFA, $E_{\text {final }}^{\prime}$ increases when the temperature increases while $E_{\text {init }}^{\prime}$ remains roughly the same. Hence $\Delta E^{\prime}$ increases;

- for a given temperature, $E_{\text {init }}^{\prime}$ slightly decreases when the DFA increases and $E_{\text {final }}^{\prime}$ decreases, thus $\Delta E^{\prime}$ decreases;

- however, the influence of an increase in DFA at $180{ }^{\circ} \mathrm{C}$ is very low compared to its influence at both $140{ }^{\circ} \mathrm{C}$ and $160{ }^{\circ} \mathrm{C}$.

In conclusion, it can be said that an increase in temperature contributes to the relative increase $\Delta E^{\prime}$ only, whereas an increase in DFA diminishes both $\Delta E^{\prime}$ and $E_{\text {init }}^{\prime}$

These trends are confirmed by the hardness measurement performed on the specimens after each test (see Fig. 12). Indeed, $H_{\text {final }}$ increases when the temperature increases, and decreases when the DFA increases. Besides, as for the $E^{\prime}$ level, the hardness is not really influenced at $180{ }^{\circ} \mathrm{C}$ by the DFA anymore.

The variations of each curve during each TMS also give some very interesting informations about the hardening kinetics. More specifically, the $E^{\prime}$ variation rate during each TS and TMS $\left(V_{E^{\prime}}^{T S}\right.$ and $\left.V_{E^{\prime}}^{T M S}\right)$ can be calculated as follows:

$$
V_{E^{\prime}}^{T S}(n)=\frac{E_{n}^{\text {init }}-E_{n}^{\text {final }}}{\Delta t_{T S}}, n=2,4,6, \ldots, 24
$$




$$
V_{E^{\prime}}^{T M S}(n)=\frac{E_{n}^{\text {final }}-E_{n}^{\text {init }}}{\Delta t_{T M S}}, n=1,3,5 \ldots, 25
$$

The obtained results are given in Figure 13. The following comments can be drawn for these results during TMS:

- for each test, during the first TMS(s) (between one and three), $E^{\prime}$ decreases (see the points with a negative coordinate on the curve with the round markers). This phenomenon is probably due to a "demullinization" followed by a general stress softening ;

- for a given force, $V_{E^{\prime}}^{T M S}$ increases when the temperature increases ;

- for a given temperature, $V_{E^{\prime}}^{T M S}$ increases when the DFA increases. This is the first feature showing a positive contribution to the hardening process.

During TS (see Figure 14);

- each $V_{E^{\prime}}^{T S}$ curve decreases (but remains positive) during the early stages of the tests, and then becomes stable;

- the order of magnitude of $V_{E^{\prime}}$ is rather different: $0-150 \mathrm{~Pa} . \mathrm{s}^{-1}$ for $V_{E^{\prime}}^{T, S}$, $1000-6000$ Pa.s $s^{-1}$ for $V_{E^{\prime}}^{T,}$;

- for the same DFA, $V_{E^{\prime}}^{T S}$ increases when the temperature increases;

- for the same temperature, $V_{E^{\prime}}^{T S}$ increases when the DFA increases. Hence the DFA level applied during the TMS has an influence on $V_{E^{\prime}}^{T S}$.

For the first time in the study, it is clearly shown that the mechanical loading has a positive action on stiffening.

The evolution of the viscoelastic parameters and the hardness undoubtedly reflects chemical changes. Suitable chemical analyses were therefore performed to investigate this issue and to evaluate the precise influence of the mechanical 
loading on vulcanization. Obtained results are presented and discussed in the next section.

\subsection{Changes in the rubber microstructure}

In the previous section, mechanical tests are analysed to investigate the material response during cyclic loading at several temperatures. It is however not sufficient, using mechanics only, to find the actual causes of the mechanical responses observed during the different types of tests. The idea here is to collect some relevant information about the chemical evolution in order to establish the link with the features of the mechanical response. FTIR spectroscopy and XPS described in Section 2 were used for this purpose.

\subsubsection{FTIR spectroscopy}

FTIR spectra are classically used to observe evolution, creation or disappearance of bonds between elements of interest, i.e. changes in the functional groups. Specimens T180F50 and T180 were analyzed after testing using the FTIR spectroscopy. The same analysis was performed on a virgin specimen to have a reference. The corresponding spectra and possible assignments are shown in Fig. 9. Comparison of the FTIR spectra for the single components of the studied materials (not shown here) and the sample after testing does not allow some clear trend to be deduced regarding the position and the relative intensities of the vibration bands. Nevertheless, it can be seen that there is a significant change of the baseline, which decreases in intensity. For each DFA, the spectrum of each specimen after test is beneath that obtained with the virgin specimen. Gunasekaran et al. [5] have studied rubber blends using FTIR 
spectroscopy. The spectra they obtained for vulcanized and reinforced blends are nearly identical. Only their absorption rates are different. The absorption was weaker for vulcanized samples. By analogy, the shift towards low absorption observed in this study could be caused by vulcanization. This feature can be the direct effect of the microstructure change described for instance in ref. [5]. This may also come from a possible modification of the contact between the sample and the diamond crystal because of the increase in rigidity. In all cases, this constitutes an indicator of the vulcanization level, may it be direct or indirect. This confirms that every combination of thermomechanical load leads to a certain progress in vulcanization. Besides, the higher the temperature, the lower the intensities of the spectra, thus meaning that the vulcanization rate increases according to the temperature. Moreover, at the same temperature, the higher the DFA, the lower the intensity of the baseline (except at $140{ }^{\circ} \mathrm{C}$ ). It means that vulcanization rate becomes greater at a higher DFA. It was not possible to guess this influence by observing the E' curves of the first series (see Figure 4), but the changes in specimen geometry may have disturbed the results for the tests at $180{ }^{\circ} \mathrm{C}$.

\subsubsection{X-ray Photoelectron Spectroscopy}

The analysis is carried out for three different specimens presented in Section 2.5. As the XPS is a surface-sensitive method that probes the composition of the outer $10 \mathrm{~nm}$ of the surface, the piece of material to be analyzed with XPS is extracted from the inside of the specimens after testing. This avoids the need to examine the chemical modifications which might occur only at the specimen surface during the test and which would not really affect the macroscopic mechanical response of the material. Thus, examining the material located in the inside of the specimen allows us to characterize the changes 
in microstructure of the bulk material.

Figures 15-(a), 15-(b), 15-(c) present high resolution XPS spectra obtained for each specimen. It should be recalled here that the regions of interest were scanned three times to get acceptable signal-to-noise ratios. Curve fitting was used to determine the change in chemical environment of the carbon atoms. These figures present the $\mathrm{C}_{1 \mathrm{~s}}$ core levels from the spectra of the virgin, T180 and T180F50 specimens. The $\mathrm{C}_{1 s}$ core level of the virgin filled nitrile can be fitted by two components. The major one corresponding to the $\mathrm{C}-\mathrm{C} / \mathrm{C}-\mathrm{H}$ bonds $(284.9 \mathrm{eV})[6]$ and the lower one, which appears as a shoulder at higher binding energies corresponds to oxidized species (C-O bonds) $\mathrm{C}-\mathrm{O}-\mathrm{C} / \mathrm{C}-\mathrm{OH}$ (286.3 eV). The $\mathrm{C}=\mathrm{C}$ bond was included in the $\mathrm{C}-\mathrm{C}$ component as the gap between these binding energies is only $0.3 \mathrm{eV}[7]$. The $\mathrm{C} \equiv \mathrm{N}$ bond from the NBR macromolecular network was not considered due to the small contribution of nitrogen to the final composition [8]. From a qualitative point of view, the curve shape and fit do not clearly change between the virgin and heated specimens. This is not really surprising since nitrile rubbers are particularly used for their ability to sustain high temperature without significant changes in their microstructure. In the literature, the change in the microstructure due to over-vulcanization or ageing is generally studied according to photoirradiation, thermal environment etc, but never according to the mechanical loading, to the best of the authors' knowledge. Nevertheless, it can be seen in Figure 15-(b), which corresponds to specimen T180F50, that the curve obtained significantly differs from the previous ones. This shows that coupling exists between chemical and mechanical effects in the microstructure changes. Indeed, a strong reduction of the component at $286.3 \mathrm{eV}$ (C-O bonds) can be observed in Figure 15-(c) along with the appearance of a new component at $288.9 \mathrm{eV}$ which can reasonably be attributed to $\mathrm{O}-\mathrm{C}=\mathrm{O}$ bounds. This is 
highlighted by the normalized $\mathrm{C}_{1 s}$ core level peak in Figure 15-(d). This modification of the macromolecular network obtained when the mechanical loading is applied can mainly be attributed to over-vulcanization reactions between NBR, sulphur, and other agents in the presence of zinc oxide and stearic acid, which confirms the FTIR spectroscopy results.

\section{Summary of the results}

Numerous results have been obtained during the three series of tests performed in this study.

- The first series consists in applying simultaneously mechanical and thermal loadings. Hardness and viscoelasticity measurements have shown that the microstructure of the material evolves significantly with temperature. The effect of of the mechanical loading is more difficult to evaluate from this type of test. FTIR investigations have shown that an over-vulcanization occurs in the material for the highest temperature levels.

- The second series corresponds to uncoupled tests. One level of temperature among three $\left(140,160\right.$ and $\left.180^{\circ} \mathrm{C}\right)$ is applied before applying a DFA of $50 \mathrm{~N}$ during one million cycles at $10 \mathrm{~Hz}$. Contrary to the first series, no flattering was observed, thus meaning that mechanical loading has some effects on the change in the microstructure.

- The third series consists in monitored uncoupled tests. The specimens are tested by applying 24 sequences of one thermomechanical step and one thermal step. Recording of E' during each thermomechanical step shows that the mechanical loading has a positive action on stiffening and consequently that the temperature is not the only factor that affects the change in the mi- 
crostructure. XPS analysis shows that the increase in the stiffness is associated with chemical modifications of the specimen due to over-vulcanization.

\section{Conclusion}

Three series of cyclic tests have been performed on filled nitrile rubber in order to discriminate the effect of the mechanical loading on the change in the microstructure of filled nitrile rubber under high temperature, typically from 140 to 180 degree Celsius. This change in the microstructure induces an increase in the storage modulus and a decrease in the loss factor, which is correlated with a hardness increase. Such evolution appears at high temperature, whatever the mechanical cyclic load (DFA) applied. However, DFA was found to modify the kinetic of change in the microstructure. Indeed, FTIR spectroscopy and XPS analyses have shown that mechanical loading induces chemical changes which are not observed if only a thermal load is applied. Consequently, this study shows that the effects of mechanical loading on filled nitrile rubber tested at high temperatures is significant and cannot be overlooked.

\section{Acknowledgements}

The authors would like to acknowledge Élodie Petit and Guillaume Monnier for their helpfull contributions to the IR spectroscopy and XPS analyses as well as the PCM company for its financial support. 


\section{References}

[1] W. V. Mars and A. Fatemi. A literature survey on fatigue analysis approaches for rubber. Int. J. Fatigue, 24:949-961, 2002.

[2] E. Ostoja-Kuczynski. Comportement en fatigue des élastomères : application aux structures antivibratoires pour l'automobile. Thèse de doctorat, École Centrale de Nantes, 2005.

[3] A. Andriyana and E. Verron. Prediction of fatigue life improvement in natural rubber using configurational stress. International Journal of Solids and Structures, 44:2079-2092, 2007.

[4] J.-B. Le Cam, E. Verron, and B. Huneau. Description of fatigue damage in carbon black filled natural rubber. Fatigue and Fracture of Engineering Materials \& Structures, 31:1031-1038, 2008.

[5] S. Gunasekaran, R.K. Natarajan, and A. Kala. FTIR spectra and mechanical strength analysis of some selected rubber derivatives. Spectrochimica Acta Part A: Molecular and Biomolecular Spectroscopy, 68(2):323 - 330, 2007.

[6] S.W. Zhang. In Tribology of Elastomers, volume 47 of Tribology and Interface Engineering Series, pages 259 - 265. Elsevier, 2004.

[7] N. Dilsiz and J.P. Wightman. Effect of acid-base properties of unsized and sized carbon fibers on fiber/epoxy matrix adhesion. Colloids and Surfaces A: Physicochemical and Engineering Aspects, 164(2-3):325 - 336, 2000.

[8] L. Martinez, R. Nevshupa, L. Alvarez, Y. Huttel, J. Mendez, E. Roman, E. Mozas, J. R. Valdes, M. A. Jimenez, Y. Gachon, C. Heau, and F. Faverjon. Application of diamond-like carbon coatings to elastomers frictional surfaces. Tribology International, 42(4):584-590, 2009. European Conference on Tribology (ECOTRIP 2007), Ljubljana, Slovenia, 2007. 


\section{List of Figures}

1 The three different types of thermomechanical loads combining F (solid line) and T (dotted line) used in the study.

2 Hardness measurements performed on specimens that sustained the coupled thermal and mechanical loadings tests

3 Elastic modulus $E^{\prime}$ obtained for the nine tests

4 Elastic modulus $E^{\prime}$ for the three tests performed at $15 \mathrm{~N}$

5 Elastic modulus $E^{\prime}$ for the three tests performed at $30 \mathrm{~N}$

6 Elastic modulus $E^{\prime}$ for the three tests performed at $50 \mathrm{~N}$

7 Elastic modulus $E^{\prime}$ for the three tests performed at $180{ }^{\circ} \mathrm{C}$

8 Height under $5 N\left(h_{-5}\right)$ for the nine tests

$9 \quad$ FTIR spectra of the surface of a virgin specimen and specimens after test performed at 140,160 and $180^{\circ} \mathrm{C}$ at $15 \mathrm{~N}$ (a), $30 \mathrm{~N}(\mathrm{~b}), 50 \mathrm{~N}(\mathrm{c})$

10 Elastic modulus $E^{\prime}$ for the controlled specimen (at ambient temperature) and for T180F50, T160F50, T140F50 at ambient and at their original temperature

11 Elastic modulus $E^{\prime}$ during the 25 thermomechanical steps for the nine sets of thermomechanical parameters

12 Evolution of the hardness versus the temperature (a) and force (b) for the nine tests 
$15 \mathrm{C}_{1 s}$ core level peak of the virgin specimen (a), the T180F50 specimen (b), the heated specimen (c) and the superimposition of the tree spectra $(d)$ 


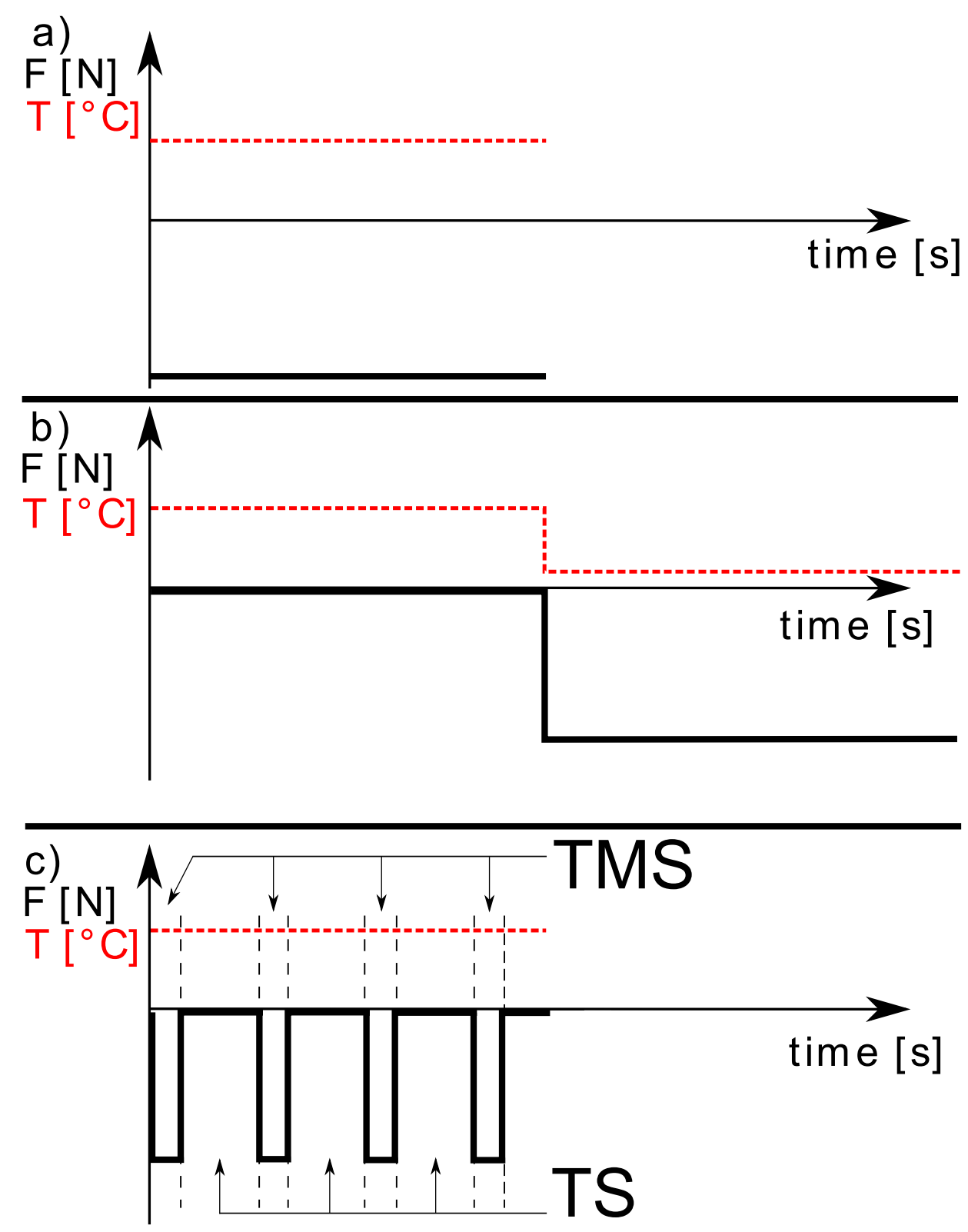

Fig. 1. The three different types of thermomechanical loads combining F (solid line) and $\mathrm{T}$ (dotted line) used in the study. 


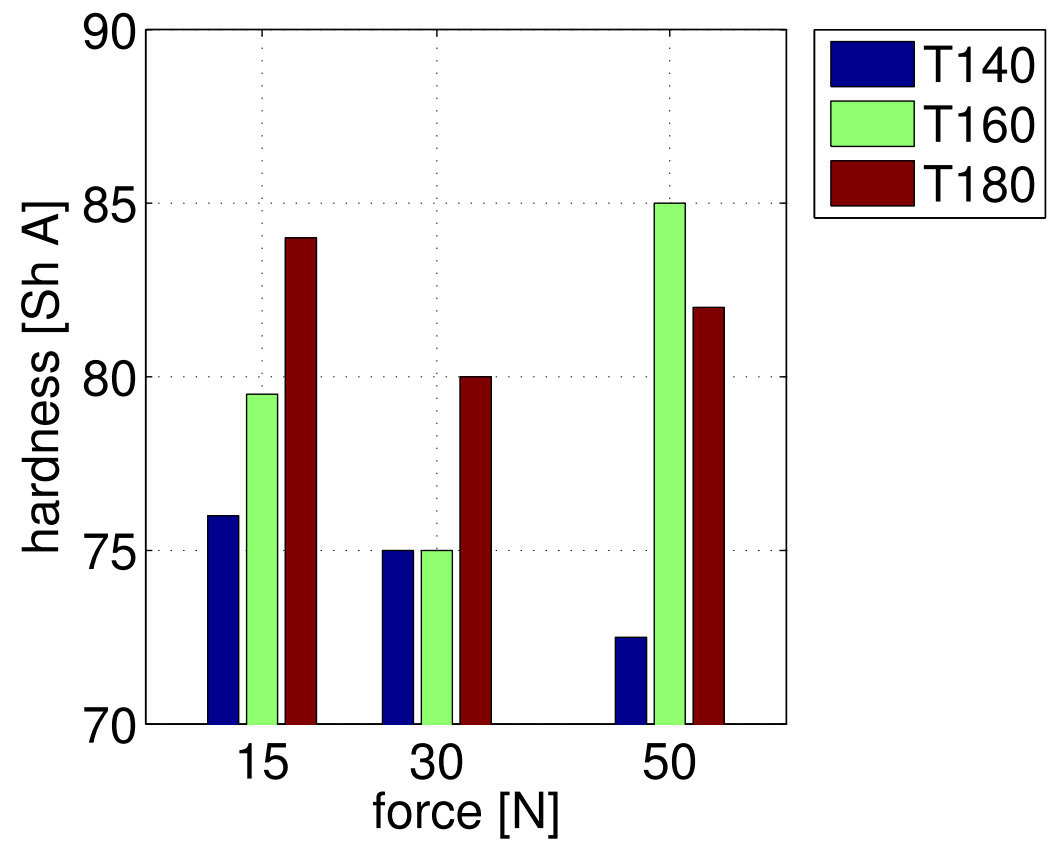

Fig. 2. Hardness measurements performed on specimens that sustained the coupled thermal and mechanical loadings tests

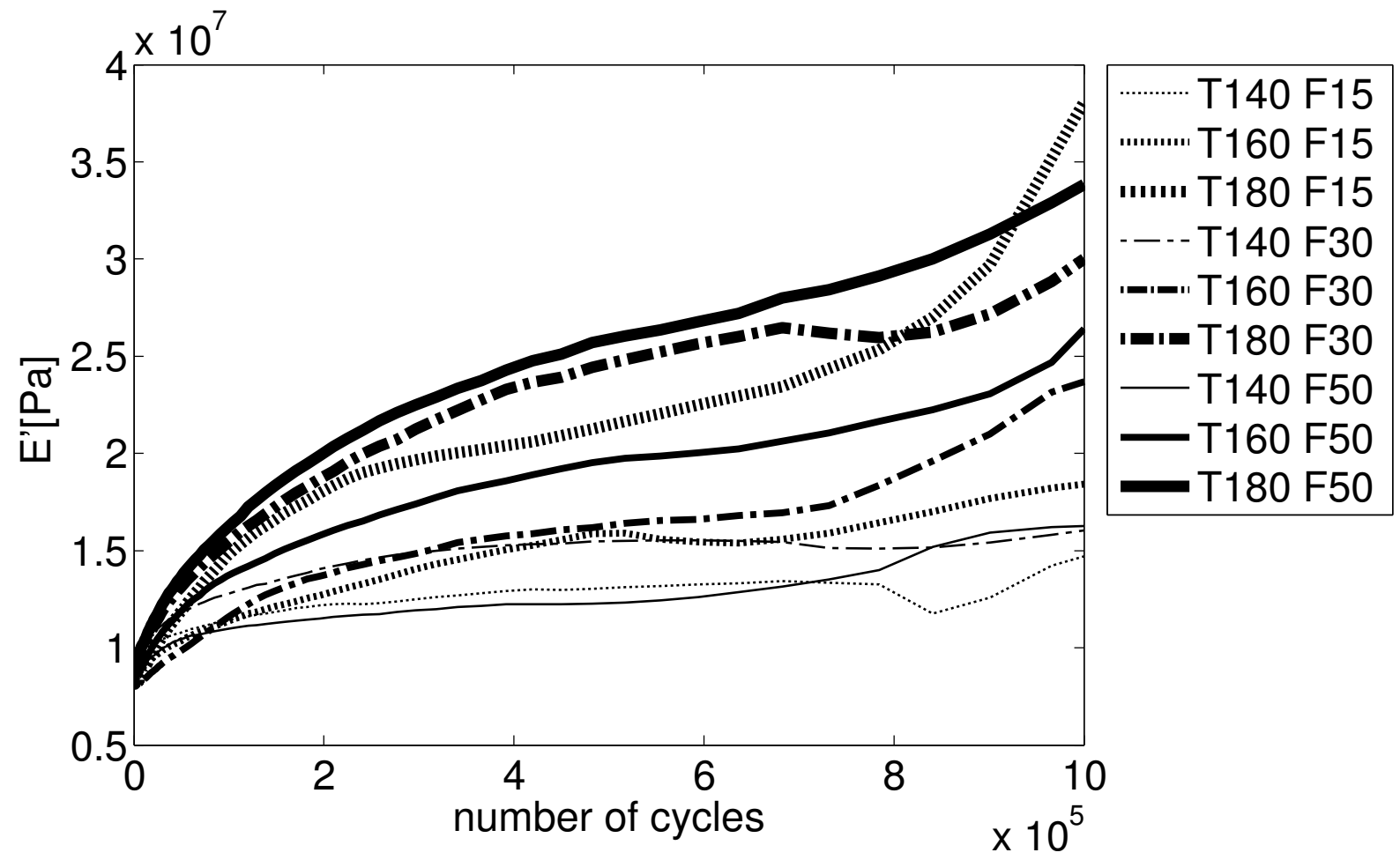

Fig. 3. Elastic modulus $E^{\prime}$ obtained for the nine tests 


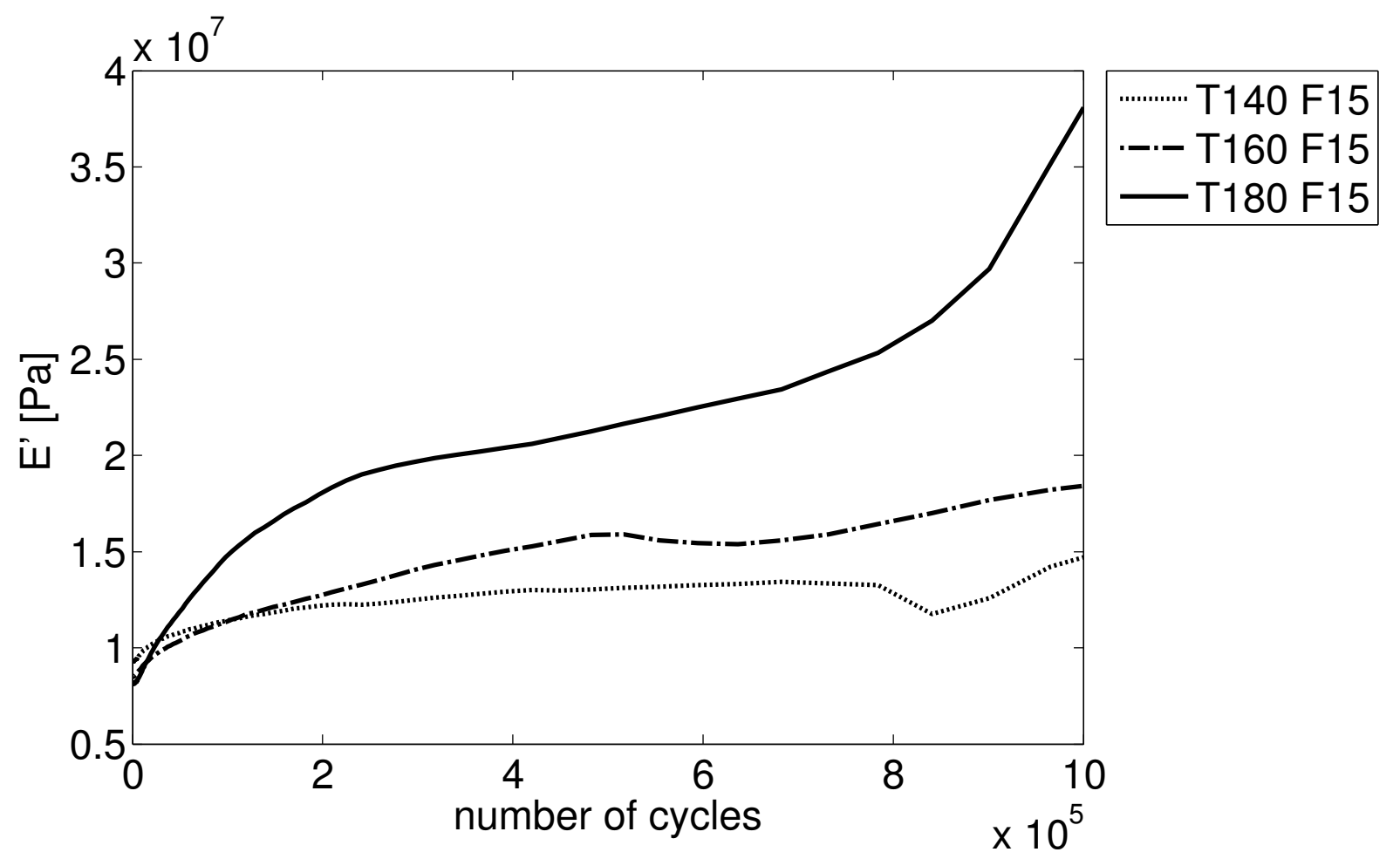

Fig. 4. Elastic modulus $E^{\prime}$ for the three tests performed at $15 \mathrm{~N}$

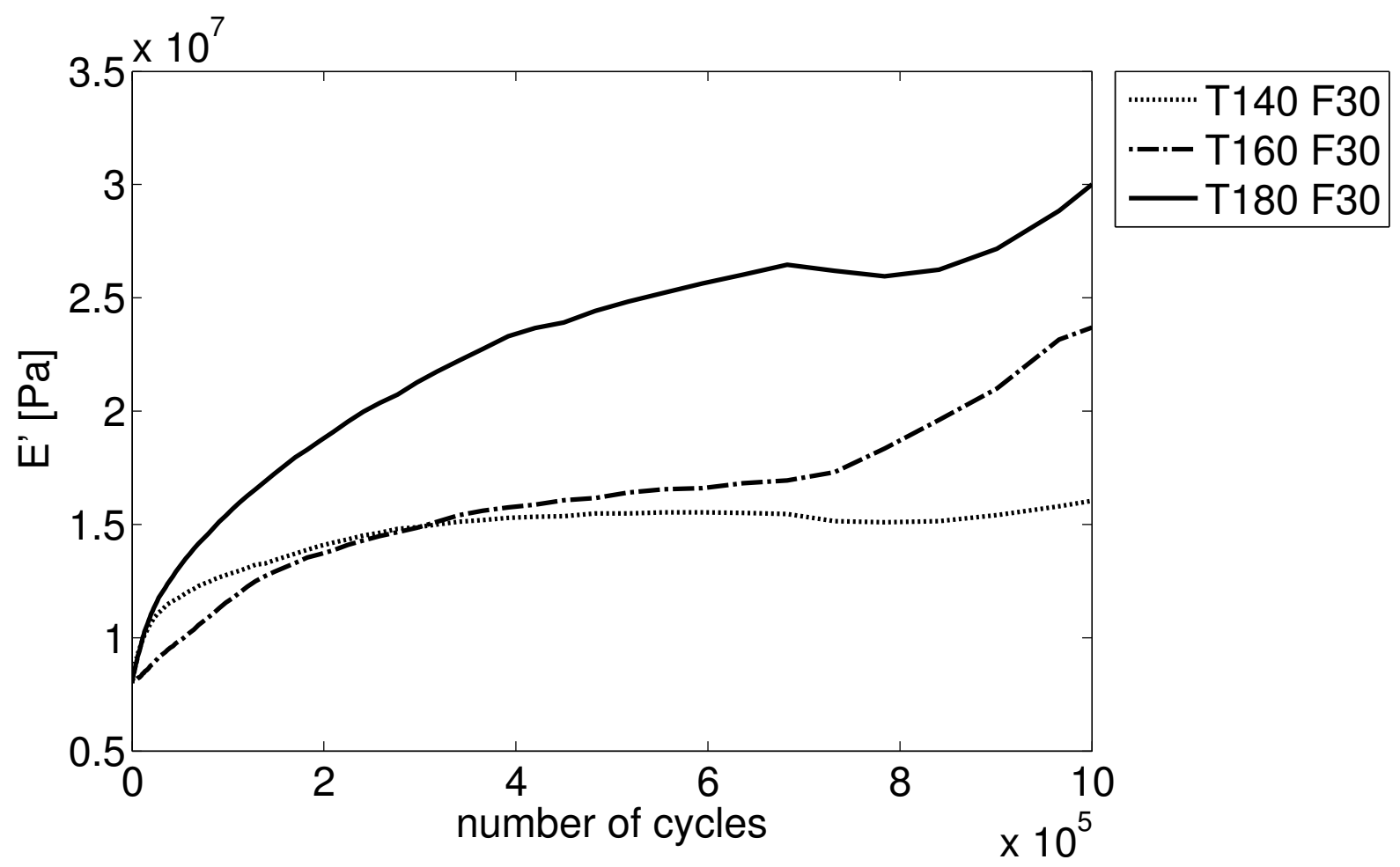

Fig. 5. Elastic modulus $E^{\prime}$ for the three tests performed at $30 \mathrm{~N}$ 


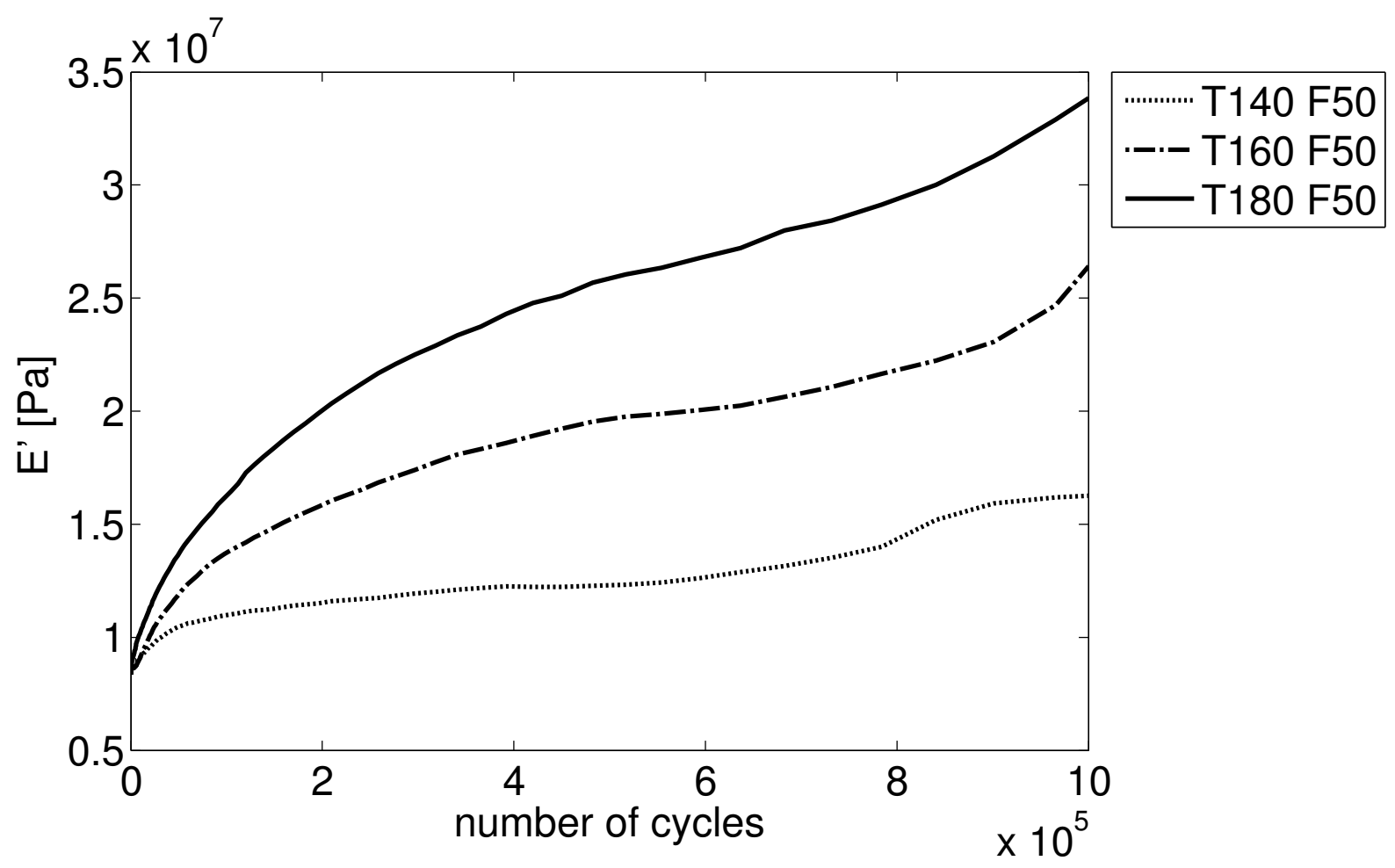

Fig. 6. Elastic modulus $E^{\prime}$ for the three tests performed at $50 \mathrm{~N}$

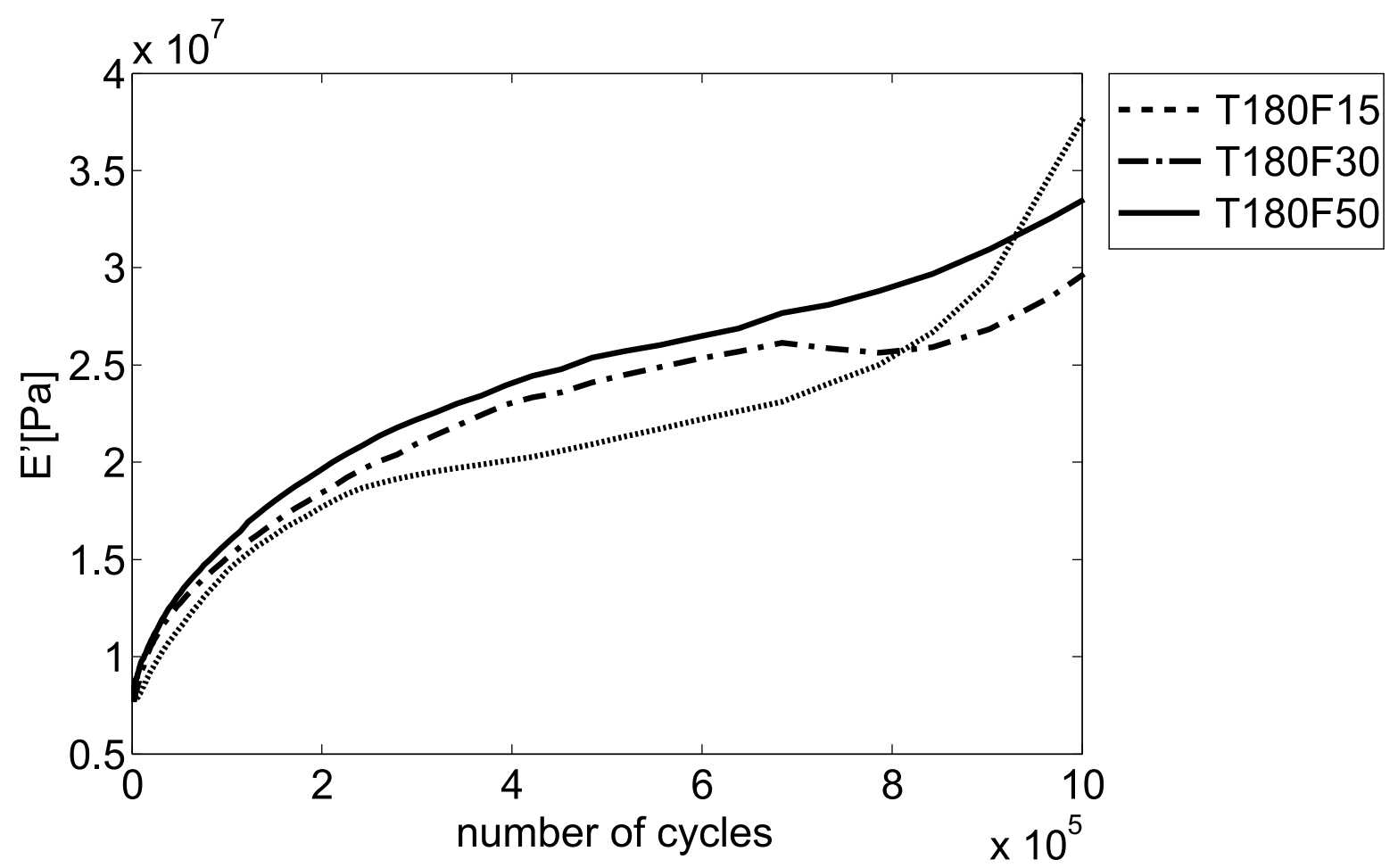

Fig. 7. Elastic modulus $E^{\prime}$ for the three tests performed at $180{ }^{\circ} \mathrm{C}$ 


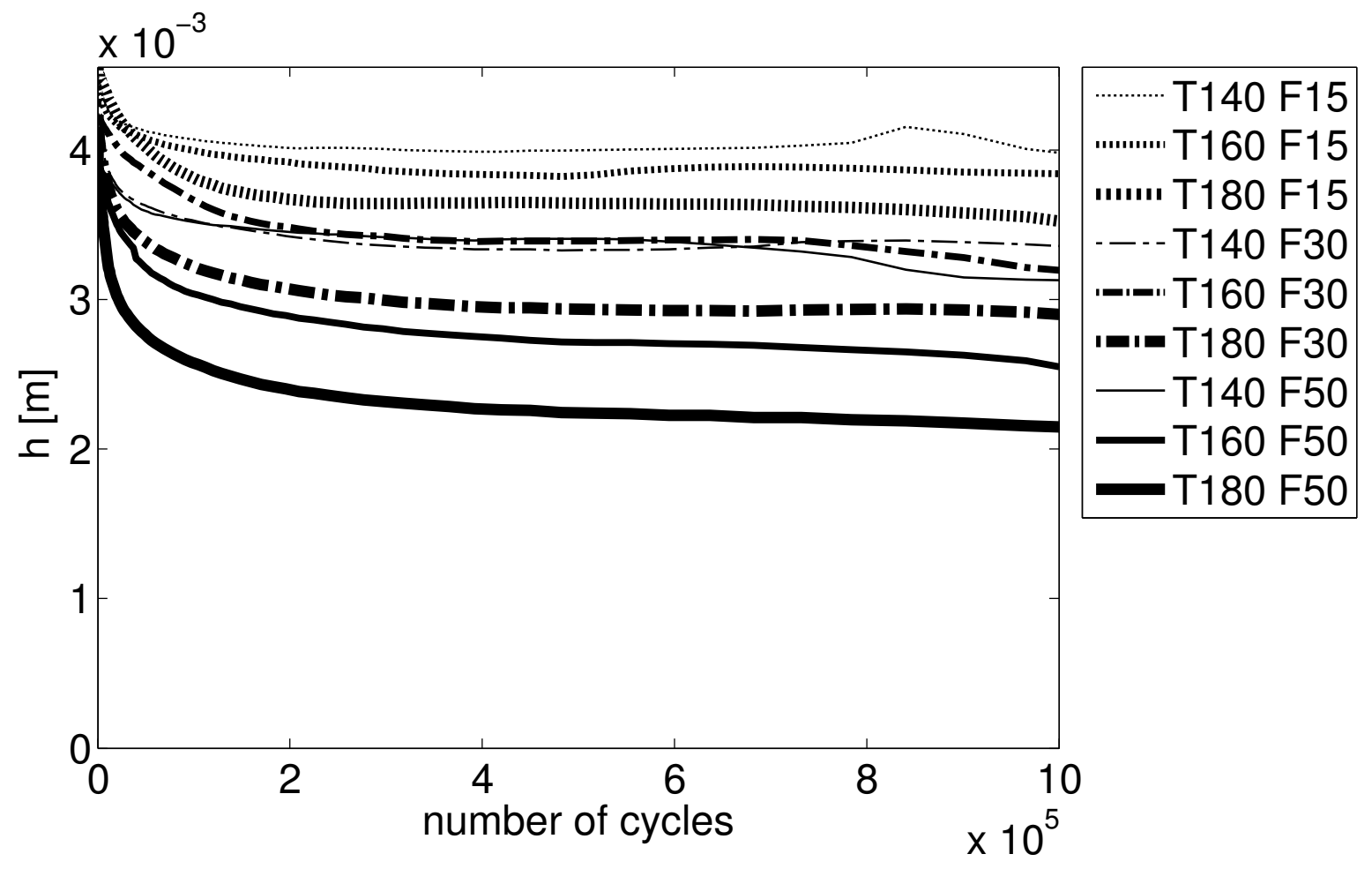

Fig. 8. Height under $5 N\left(h_{-5}\right)$ for the nine tests 


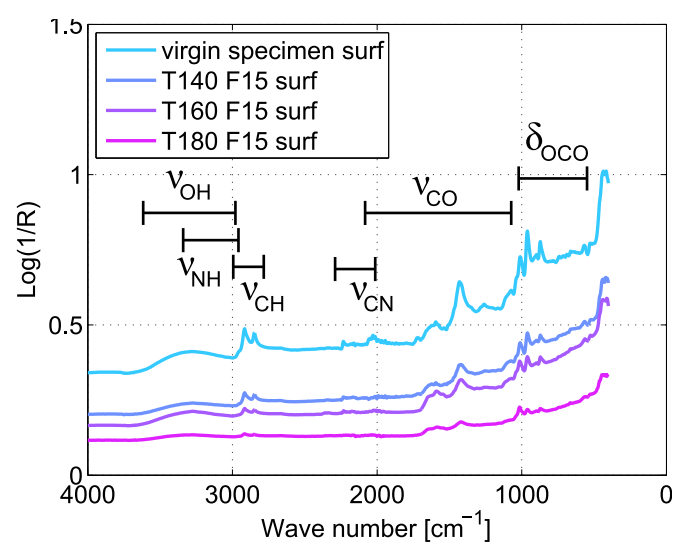

(a) $15 \mathrm{~N}$

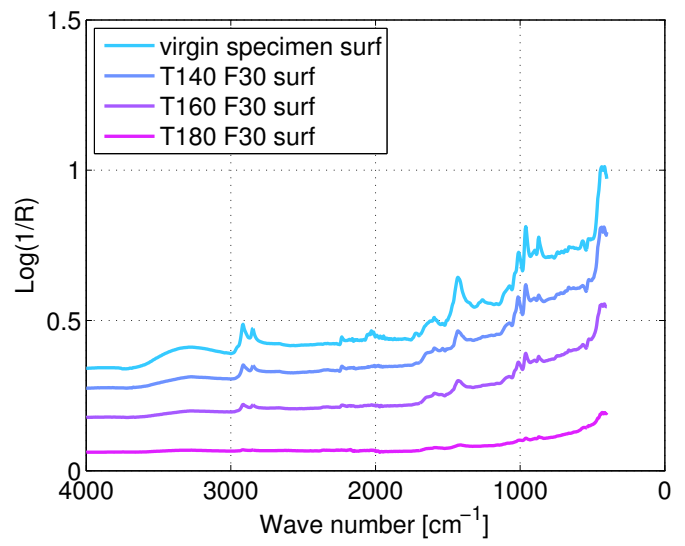

(b) $30 \mathrm{~N}$

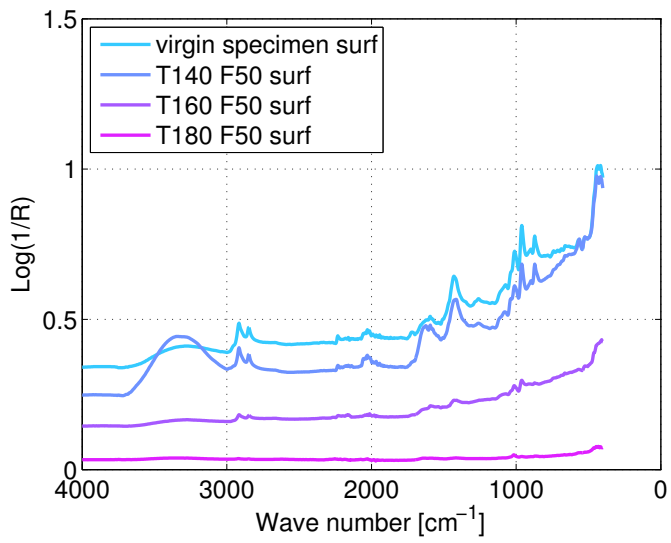

(c) $50 \mathrm{~N}$

Fig. 9. FTIR spectra of the surface of a virgin specimen and specimens after test performed at 140,160 and $180^{\circ} \mathrm{C}$ at $15 \mathrm{~N}(\mathrm{a}), 30 \mathrm{~N}(\mathrm{~b}), 50 \mathrm{~N}$ (c) 


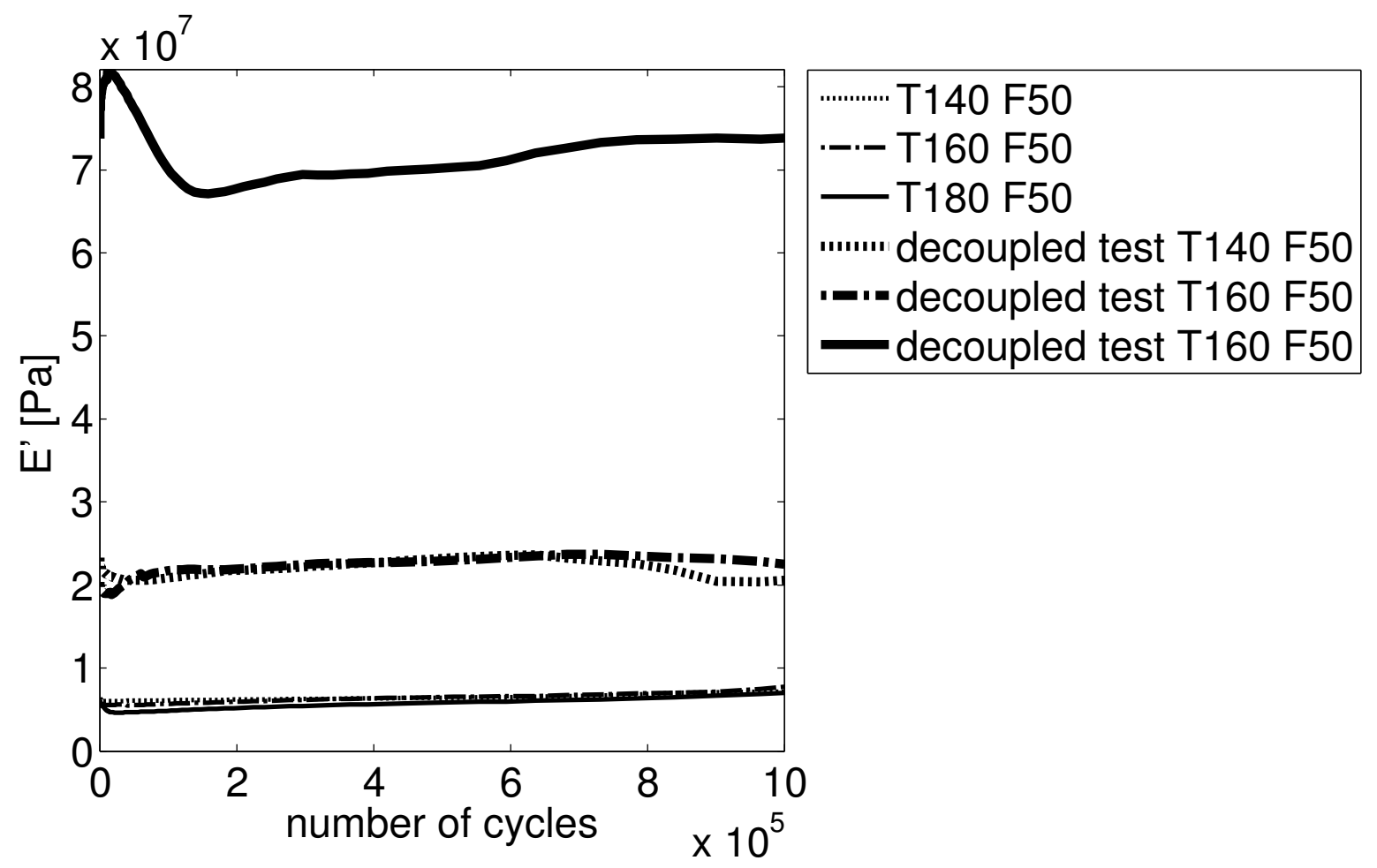

Fig. 10. Elastic modulus $E^{\prime}$ for the controlled specimen (at ambient temperature) and for T180F50, T160F50, T140F50 at ambient and at their original temperature 

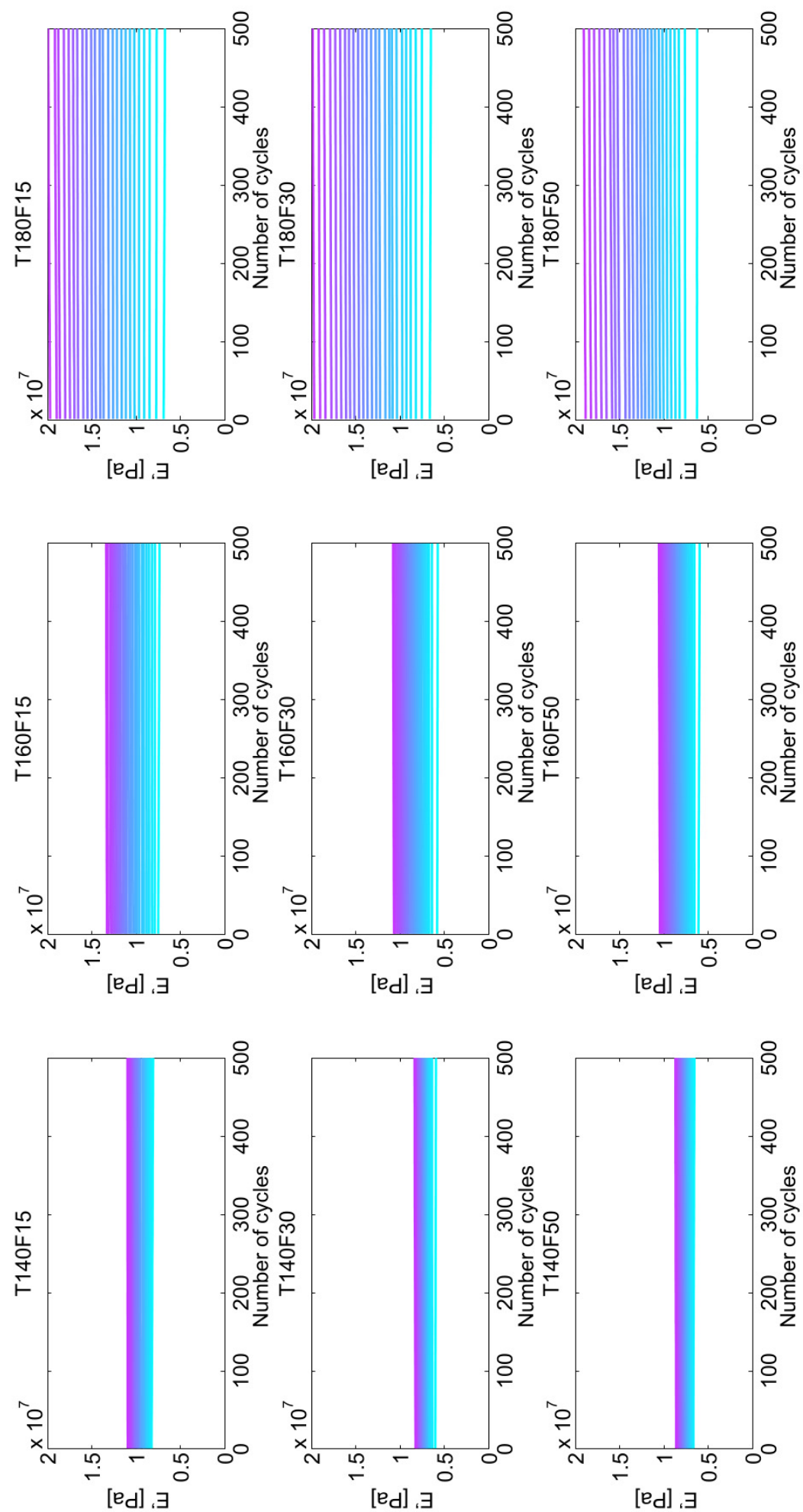

Fig. 11. Elastic modulus $E^{\prime}$ during the 25 thermomechanical steps for the nine sets of thermomechanical parameters 


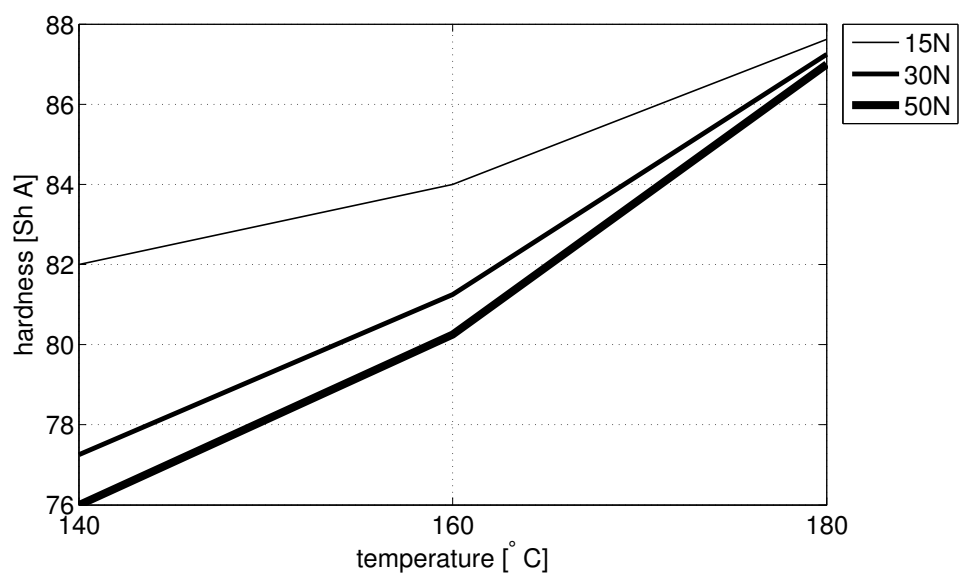

(a) hardness vs temperature

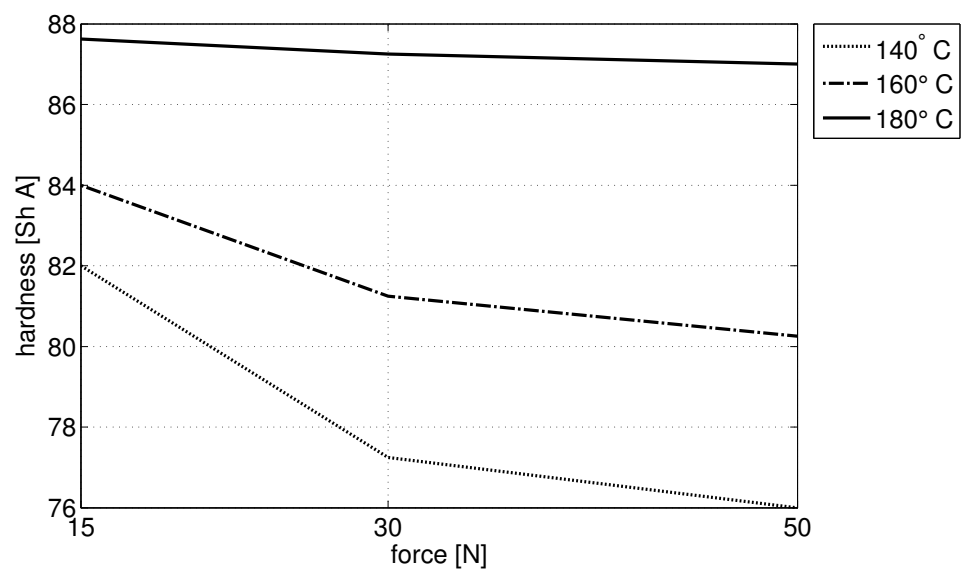

(b) hardness vs force

Fig. 12. Evolution of the hardness versus the temperature (a) and force (b) for the nine tests 

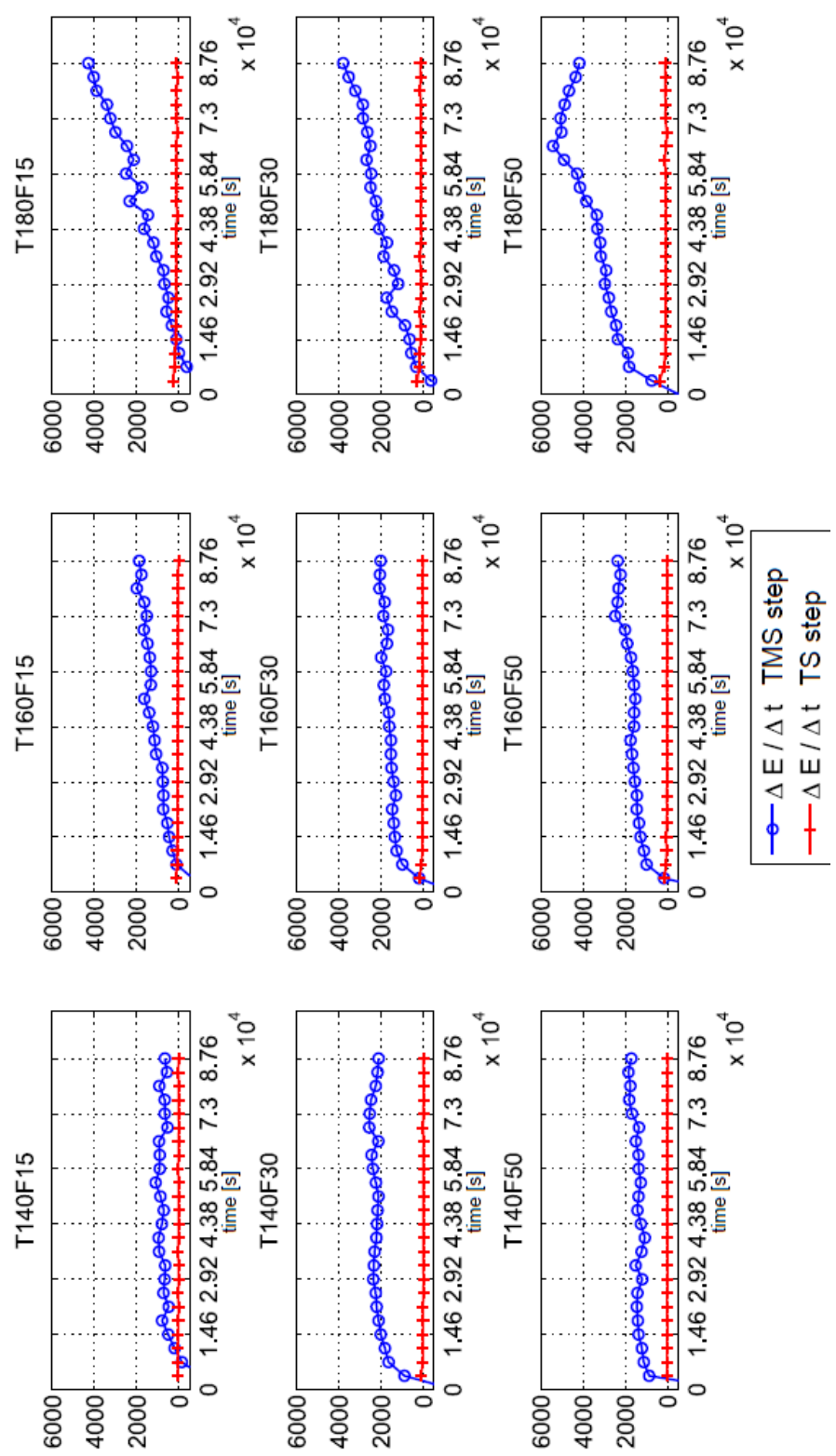

Fig. 13. Evolution of the variation rate of $E^{\prime}$ during each TS and TMS 


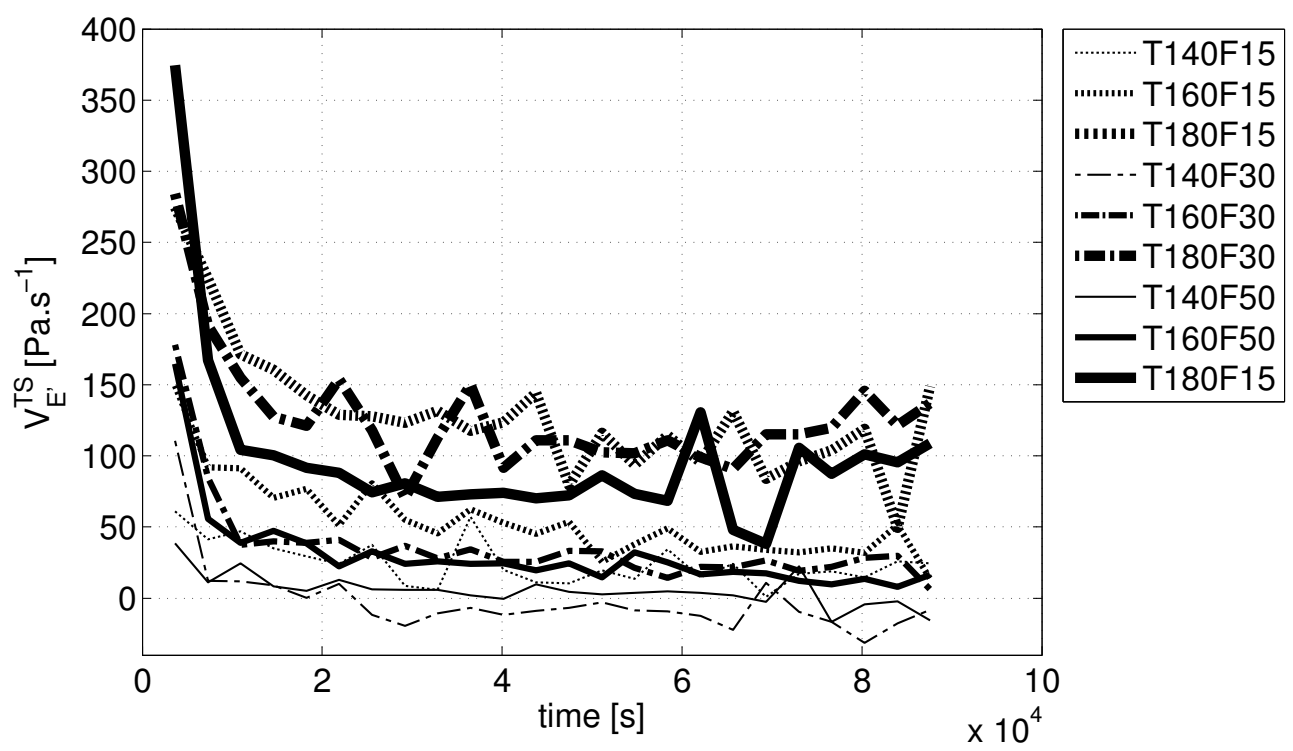

Fig. 14. Evolution of the variation rate of $E^{\prime}$ during each TS 


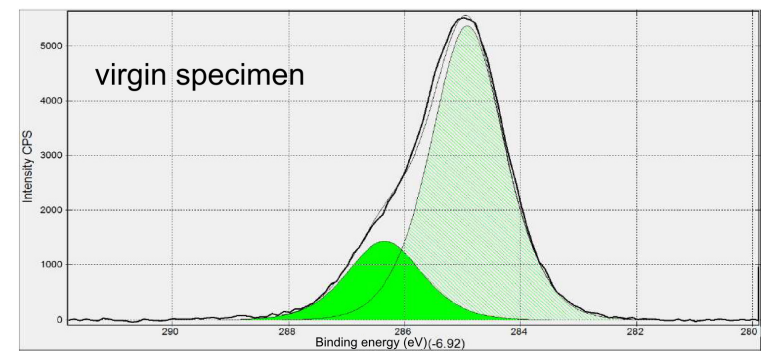

(a)

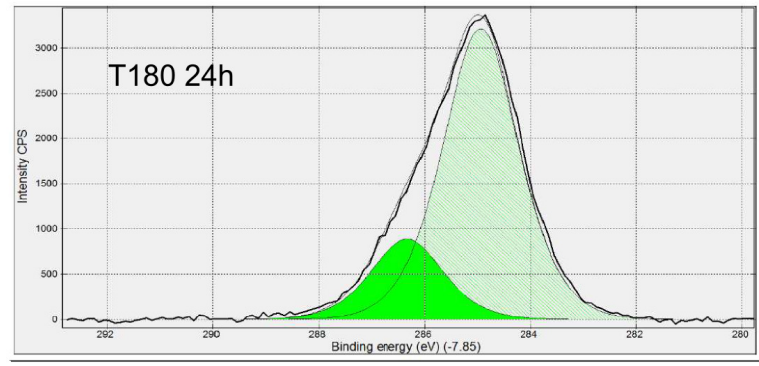

(b)

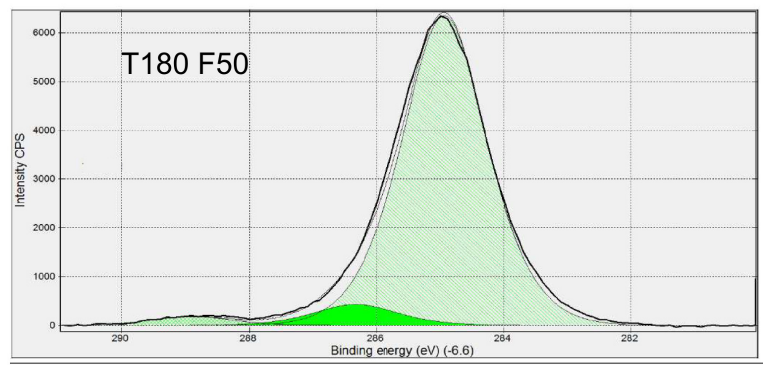

(c)

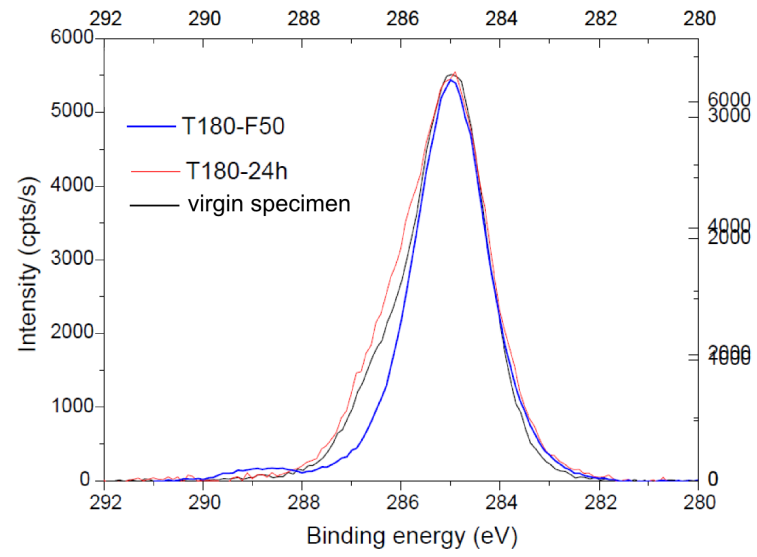

(d)

Fig. 15. $\mathrm{C}_{1 s}$ core level peak of the virgin specimen (a), the T180F50 specimen (b), the heated specimen $(\mathrm{c})$ and the superimposition of the tree spectra $(\mathrm{d})$ 